\title{
The Effect of Smoking (Cigarette and Marijuana) on Peak Expiratory Flow Rate
}

\section{*Nwozor C.M., Obiechina M.C., Dike P.N., Orakwue S.E., and Ifedi I.C.}

\author{
Department of Physiology, Faculty of Medical Sciences, Chukwuemeka Odumegwu Ojukwu \\ University, Uli Campus. Anambra State, Nigeria.
}

Article No.: 031218041

Type: Research

DOI: 10.15580/GJEPH.2018.2.031218041

Submitted: $12 / 03 / 2018$

Accepted: $26 / 03 / 2018$

Published: 31/03/2018

${ }^{*}$ Corresponding Author

Nwozor C.M.

E-mail: corneliusnwozor@gmail.com

Keywords: Smoking, marijuana, cigarette, PEFR, and non-smokers
Smoking has been recognized as a major risk factor for respiratory diseases especially, chronic obstructive airway disease, lung cancer and cardiovascular diseases. This study was undertaken to investigate the effects of smoking (cigarette and marijuana) on the peak expiratory flow rate among undergraduates. The study was carried out at both campuses (Igbariam and Uli) of Chukwuemeka Odumegwu Ojukwu University, Anambra state. Three hundred and fifty (350) students participated in the study after informed consent was obtained. The respondents were divided into four groups. Group A consisted of cigarette smokers. Group B was marijuana smokers. Group C was cigarette and marijuana smokers. Group D was control (non-smokers).Questionnaires were distributed to the respondents.ASSESS peak flow meter (RESPIRONICS, U.S.A) was used to measure peak expiratory flow rate (PEFR).The results revealed that cigarette smokers had a mean PEFR of $396 \pm 12$ LPM. Marijuana smokers had a mean PEFR of $586 \pm 16$ LPM. Cigarette and marijuana smokers had a mean PEFR of $555 \pm 20$ LPM. The control (non-smokers) had a mean PEFR of $506 \pm 12$ LPM. Cigarette smoking significantly decreased PEFR, while marijuana smoking had a positive effect on PEFR. 


\section{INTRODUCTION}

Cigarette smoking is rampant across the globe. It is a dangerous practice that is associated with serious health hazards. Manufacturers of tobacco spend huge sums of money in advertising in order to maintain their market share. Youths are the target population. They have continued to smoke despite warnings. This is principally because smoking is associated with addiction. Many countries have taken steps to control the consumption of tobacco with usage and sales restrictions; including warning messages printed on packaging. Tobacco smoke contains nicotine and several carcinogenic chemicals. Nicotine is highly addictive psychoactive drug. Therefore cigarette smoking results in the nicotine content causing physical and psychological dependence (Nichter et al., 1991).

According to World Health Organization (WHO, 2008)) tobacco use is the single greatest cause of preventable death globally. Cigarette smoking is a major risk factor for chronic obstructive pulmonary disease (COPD), emphysema, cardiovascular diseases, cancers of the larynx and mouth (Villeneuve and Mao, 1994). High mortality has been associated with smoking. Each cigarette that is smoked is estimated to shorten life by an average of 11minutes (BBC News, 1999).Smokers are three times as likely to die before the age of 60 or 70 unlike non-smokers (Doll et al., 2004; Mamun et al., 2004; Thun et al., 1995).

Marijuana (Cannabis sativa) is often consumed for its mental and physical effects, such as 'high' or 'stoned' feeling, a general change of conscious perception, heightened mood. Onset of effects is within minutes when smoked and about 30minutes when eaten as a cooked cannabis edible (Riviello and Ralph, 2010).It is typically smoked with larger puff and inhaled volumes and approximately five times longer breathholding times than tobacco cigarettes of the same weight, resulting in about four times greater deposition of tar in the lung ( $\mathrm{Wu}$ et al., 1988). The volatile and particulate phase components of the smoke from each are qualitatively similar, with the major exceptions being that tobacco contains nicotine not found in marijuana and marijuana contains more than 60 cannabinoid compounds not found in tobacco (Douglas et al., 2015).

Peak Expiratory Flow Rate (PEFR) is a useful parameter to monitor airway obstruction, assess its severity and variation and evaluate the effects of treatment (ATS, 1994; Birajdar et al., 2016).PEFR measures the maximal airflow rate achieved while forcefully expelling air from the lungs, following maximal inspiration. Tests of PEFR reflect changes in airways caliber, often expressed as liters/minute (Sagher et al., 1999). This research was undertaken to evaluate the effects of smoking (cigarette and marijuana) on peak expiratory flow rate among students of Chukwuemeka Odumegwu Ojukwu (at both Uli and Igbariam campuses).Anambra state, Nigeria.

\section{MATERIALS AND METHOD}

\section{Study Area}

The research was carried out at Chukwuemeka Odumegwu Ojukwu University, Uli and Igbariam campuses. The university operates a two-campus system with the main campus at Igbariam.350 students were recruited into the study after informed consent was obtained.

\section{Instrument of Data Collection}

- Questionnaire. A questionnaire was designed to capture the following relevant information: age, gender, height, department, smoking habit and duration

- Peak flow meter. ASSESS peak flow meter (RESPIRONICS, U.S.A) was used. A peak flow meter is an apparatus used to measure the flow of air as it is expelled from the lungs.

- A tape rule. The tape rule was used to measure the height of the respondents. This is necessary because the peak flow meter has specific height in which measurements are to be taken

\section{Method of Data Collection}

During data collection, the following procedure was employed. Two trained research assistants went to the different lodges and hostels located at both Uli and Igbariam campuses of the university. A student who willingly agreed to participate in the study was given a questionnaire to fill. The tape rule was used to measure his height. Before an individual was tested with the peak flow the height and age were recorded, so as to determine the average points in which the markers were to be placed. The apparatus was made up of 3 markers which were colored

Green $\rightarrow$ Good
Yellow $\rightarrow$ Average
Red $\rightarrow$ Bad.

A person using the apparatus would expire air 3 times. The first trial is known as the testing phase while the second and third trials are the phases that would be taken into consideration with the mean recorded.

\section{Ethical Consideration}

Those who were recruited into the study willingly gave their informed consent. The procedure was explained to them. Steps were taken to ensure good hygiene when using the apparatus. The study was approved by the Ethical Committee of Faculty of Medical Sciences, Chukwuemeka Odumegwu Ojukwu University, Uli campus. 


\section{Experimental Design}

The participants were divided into four groups: Group A (Cigarette smokers $=100$ ); Group B (Marijuana smokers, $n=100$ ); Group C (Cigarette and Marijuana smokers, $n=100)$; Group D (Control, $n=50$ ).

\section{Statistical Analysis}

The data obtained were entered in a Microsoft Excel spreadsheet, in which tables were constructed. Parameters such as mean, percentages and standard deviations were calculated. The student's t-test was applied and $p$-values were determined. Differences were considered significant at $p<0.05$

\section{RESULTS}

The results showed that those within the age range of $19-14$ was $280(80 \%), 25-30$ age range was $58(16.6 \%)$, above 30 age range was $12(3.4 \%)$. The age range with the highest percentage of respondents was 19-24, as illustrated in table 1.

Table 1: Showing age distribution of the respondents

\begin{tabular}{|l|l|l|}
\hline Age range & Number & Percentage $(\%)$ \\
\hline $19-24$ & 280 & 80 \\
\hline $25-30$ & 58 & 16.6 \\
\hline $31 \&$ above & 12 & 3.4 \\
\hline
\end{tabular}

The number of respondents that smoked above 2 sticks of cigarette per day was $65(18.6 \%)$, while the number that smoked occasionally and less than 2 sticks per day was $85(24.3 \%)$. The number of respondents that smoked above 2 wraps of marijuana per day was 137 (39.1\%), while the number that smoked occasionally and less than 2 wraps per day was $63(18 \%)$. This is illustrated in table II.

Table II: Showing quantity smoked (cigarette and marijuana)

\begin{tabular}{|l|l|l|}
\hline & Above 2 per day & $\begin{array}{l}\text { Occasionally, less than } 2 \text { per } \\
\text { day }\end{array}$ \\
\hline Cigarette & $65(18.6 \%)$ & $85(24.3 \%)$ \\
\hline Marijuana & $137(39.1 \%)$ & $63(18 \%)$ \\
\hline
\end{tabular}

Respondents who had smoked for the duration of 0-1 year were $49(14 \%)$. Those whose duration was 2-4 years were 121 (34.6\%). Respondents who had smoked for 5yrs and above were 80 (22.9\%), as illustrated in table III.

Table III: Showing duration of smoking

\begin{tabular}{|l|l|l|}
\hline Years & Number & Percentage $(\%)$ \\
\hline $0-1$ & 49 & 14 \\
\hline $2-4$ & 121 & 34.6 \\
\hline $5 \&$ above & 80 & 22.9 \\
\hline
\end{tabular}

The peak flow readings were recorded in liter per minute (LPM). These varied among the different groups. Group A (Cigarette smokers) had a mean value of $396 \pm 12$ LPM. Group B (Marijuana smokers had a mean value of
$586 \pm 16$ LPM. Group C (Cigarette and Marijuana smokers) had a mean value of $555 \pm 20$ LPM. Group D (Control) had a mean value of $506 \pm \mathrm{LPM}$, as illustrated in table IV.

Table IV: Showing Peak Expiratory Flow Rates (PEFR)

\begin{tabular}{|l|l|l|}
\hline Groups & PEFR (L/Minute) & P-value relative to control \\
\hline A (Cigarette smokers) & $396 \pm 12$ & 0.01 \\
\hline B (Marijuana smokers) & $586 \pm 16$ & 0.01 \\
\hline $\begin{array}{l}\text { C (Cigarette and Marijuana } \\
\text { smokers) }\end{array}$ & $555 \pm 20$ & 0.03 \\
\hline D (Control) & $506 \pm 12$ & \\
\hline
\end{tabular}




\section{DISCUSSION}

The effect of smoking on peak expiratory flow rate (PEFR) was investigated. The results showed variations among the different groups of respondents. Group B (Marijuana smokers had the highest mean value of 586 \pm 16 LPM, followed by Group C (Marijuana and Cigarette smokers) with mean value of $555 \pm 20$ LPM. Group A (Cigarette smokers) had the lowest mean value of 396 \pm 12 LPM. The peak flow meter has three indicators: Green, Yellow, and Red. The green indicator indicates good expiratory airflow, the yellow indicates moderate while red indicates bad expiratory airflow. With the average age and height of this study, the good was 594 LPM, the moderate was 475LPM and the bad was 297 LPM. Cigarette smokers were within the red indicator (396 \pm 12 LPM).Group B were within the yellow indicator range, though close to the green indicator $(586 \pm 16$ LPM).Group C respondents were within the yellow indicator range (555 \pm 20 LPM).Group D had value within the yellow indicator range. Our control varied from the normal value of the manual. This may be due to differences in the population.

In comparison, the average PEFR of cigarette smokers was low compared with that of marijuana smokers. Although marijuana and tobacco have similar amounts of volatile and tar components, the pulmonary effects differ (Tashkin, 2013).Marijuana exposure has an immediate and modest bronchodilator effect with a subsequent increase in airway inflammation and symptoms of chronic bronchitis. The results showed that the PEFR of marijuana smokers was significantly higher than that of the control subjects. This is due to the fact that short term use of marijuana is associated with bronchodilation (Tetrault, 2007). The acute bronchodilator effect appears to be due to tetrahydrocannabinol (THC), the psychoactive ingredient in marijuana (Kempker et al., 2015).

The PEFR of cigarette smokers was significantly lower than that of the control subjects. This is due to the fact that cigarette smoke exposure has irritant effects which can induce acute bronchospasm by stimulating airway cholinergic reflex mechanisms (Nadal and Comroe, 1961).

In this present study marijuana smokers had higher PEFR than Group C (Cigarette and Marijuana smokers) which was higher than the control subjects. Whereas acute marijuana exposure has consistently been associated with improvements in forced expiratory volume (FEV1), peak flow measurements, and airway conductance (Tetrault et al., 2007), long-term use of smoked marijuana has been linked with symptoms of chronic bronchitis (Tashkin et al., 1987), some decrease in lung function (Tashkin, 2013; Tetrault et al., 2007).

\section{CONCLUSION}

Marijuana has a positive effect on PEFR. This may be due to the tetrahydrocannabinol (THC) it contains.
Cigarette smokers had significantly decreased PEFR compared with control subjects. This could be due to the irritant effects of the components of tobacco on the airways. Despite the apparent positive effects of marijuana smoke on PEFR, prolonged exposure to marijuana smoke (based on number of years consumed) is associated with chronic respiratory symptoms like chronic cough, sputum production, wheeze, chest tightness and dyspnea followed by reduced expiratory airflow (Douglas et al., 2015).

\section{REFERENCES}

American Thoracic Society (1994).Standardization Of Spirometry, Update. Amer J. Respir. Critical Care Med, 152:1107-36.

Birajdar G., Wagh P., Nagavekar M., (2016). Effect Of Smoking on Peak Expiratory Flow Rate. IOSR Journal of Dental and Medical Sciences (IOSRJDMS) 15 (10):92-95.

Centers for Disease Control and Prevention (CDC) (2002).Annual Smoking- Attributable Mortality, Years of Potential Life Lost, And Economic Costs- United States, 1995-1999.MMWR Morbidity and Mortality Weekly Report 51(14): 300-3.

Doll R., Peto R., Boreham J., Sutherland I., (2004).Mortality In Relation To Smoking: 50 Years' Observations on Male British Doctors. BMJ 328 (7455): 1519.

Douglas I.S., Albertson T.E., Folan P., Hanania N.A., Tashkin D.P., Upson D.J., and Leone F.T., (2015).Implications Of Marijuana Decriminalization On The Practice Of Pulmonary, Critical Care, And Sleep Medicine; A Report Of The American Thoracic Society Marijuana Workshop. Annals ATS 12 (11): 1700-1710.

Kempker J.A., Honig E.G., Martin G.S. (2015).The Effects of Marijuana on Expiratory Airflow. A Study of Adults Who Participated in the U.S National Health and Examination Study. Annals ATS Volume 12(2):135-141.

Mamun A.A., Peters A., Barendregt J., Willekens F., Nusselder W., Bonneux L., (2004).Smoking Decreases The Duration Of Life Lived With And Without Cardiovascular Disease: A Life Course Analysis Of The Framingham Heart Study. European Heart Journal 25(5): 409-415.

Nadal J.A., and Comroe J.H jr. (1961).Acute Effects of Inhalation of Cigarette Smoke on Airway Conductance. Appl. Physiol. 16:713-716.

Nichter M., Cartwright E., Cartwright (1991).Saving The Children for the Tobacco Industry.Medical Anthropology Quarterly 5(3):236-56.

Riviello R.J. (2010).Manual Of Forensic Emergency Medicine: A Guide for Clinicians. Sudbury Mass.: Jones and Bartlett Publishers. 41.

Sagher F.A., Roushadi M.A., and Hweta A.M., (1999).Peak Expiratory Flow Rate Nomogram in Libyan School Children. J. Pediatrics, 5:60-564. 
Tashkin D.P., (2013).Effects Of Marijuana Smoking on the Lung. Ann. Am. Thorac Soc. 10: 239-247.

Tashkin D.P., Coulson A.H., Clark V.A., Simmons M. Bourque L.B., Duann S. Spivey G.H., Gong H., (1987).Respiratory Symptoms And Lung Function In Habitual Heavy Smokers Of Marijuana Alone, Smokers Of Marijuana And Tobacco, Smokers Of Tobacco Alone, And Non-Smokers. Am. Rev. Respir. Dis. 135:209-216.

Tetrault J.M., Crothers K., Moore B.A., Mehra R., Concato J., Flellin D.A., (2007).Effects Of Marijuana Smoking On Pulmonary Function And Respiratory Complications: A Systematic Review. Arch Intern Med. 167:221-228.
Thun M.J., Day-Lally C.A., Calle E.E., Flanders W.D., Heath C.W. (1995). Excess Mortality Among Cigarette Smokers: Changes In A 20-Year Interval. American Journal of Public Health 85(9): 1223-30.

Villeneuv P.J., and Mao Y., (1994).Lifetime Probability of Developing Lung Cancer by Smoking Status, Canada. Canadian Journal of Public Health 85 (6): 385-8.

World Health Organization (2008). WHO Reports on the Global Tobacco Epidemic: The MPOWER Package (PDF).Geneva: World Health Organization, p.8.

Wu T.C., Tashkin D.P., Djahed B., Rose J.E., (1988).Pulmonary Hazards Of Smoking Marijuana As Compared With Tobacco. N. Engl. J. Med. 318: 347-351.

Cite this Article: Nwozor C.M., Obiechina M.C., Dike P.N., Orakwue S.E., Ifedi I.C. (2018). The Effect of Smoking (Cigarette and Marijuana) on Peak Expiratory Flow Rate. Greener Journal of Epidemiology and Public Health, 6(2): 7579, http://doi.org/10.15580/GJEPH.2018.2.031218041. 